\title{
Egyptian Mathematics
}

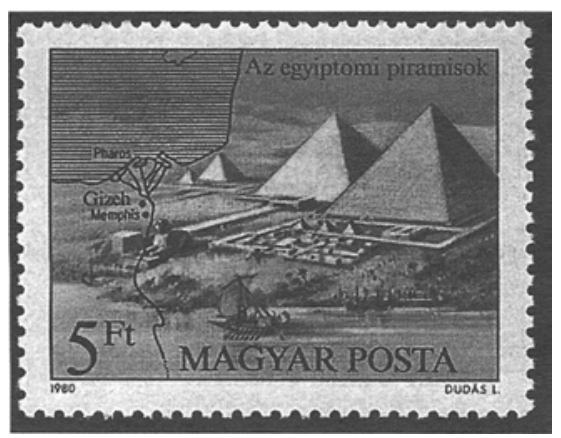

Pyramids of Gizeh

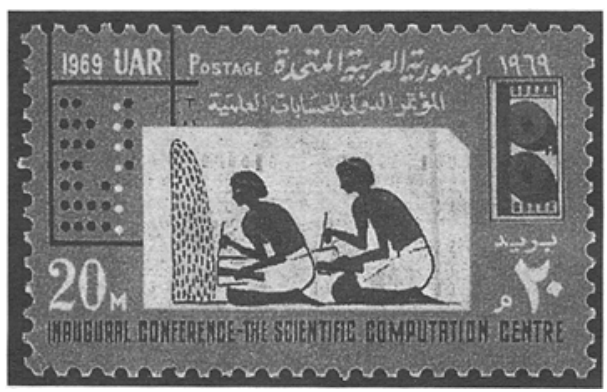

Egyptian scribes/accountants

Please send all submissions to the Stamp Corner Editor, Robin Wilson, Faculty of Mathematics and Computing, The Open University, Milton Keynes, MK7 6AA, England
$\boldsymbol{T}$ he main achievements of early Egyptian mathematicians involved the practical skill of measurement. The magnificent pyramids of Gizeh (or Giza) date from about 2600 $\mathrm{BC}$ and attest to this extremely accurate measuring ability. In particular, the Great Pyramid of Cheops, constructed from over two million blocks averaging over 2 tons in weight, has a square base of side 755 feet, where the sides agree in length to within $0.01 \%$ and the right angles are equally accurate. The oldest pyramid is King Djoser's step pyramid in Saqqara, which dates from about $2700 \mathrm{BC}$; it was supposedly designed by the celebrated court physician and architect Imhotep.

Our knowledge of later Egyptian mathematics derives mainly from just two primary sources, the 'Moscow papyrus' (c.1850 BC) and the "Rhind papyrus" (c. 1650 BC). These papyri contain tables representing certain numbers as "unit fractions" (reciprocals) and include a variety of problems in arithmetic and geometry, probably designed for the teaching of scribes. These problems range from the sharing of loaves in specified proportions to finding the volume of a cylindrical granary; the latter gives rise to a value for $\pi$ of $256 / 81(\simeq 3.16$ ).

Among other Egyptians interested in mathematics was Amenhotep (c. $1400 \mathrm{BC}$ ), a high official during the reign of Amenhotep III. During the Ptolemaic era 1000 years later his name came to be associated with the ibis-headed Thoth, god of reckoning. 